Review

\title{
Post-Surgical Clinical Monitoring of Soft Tissue Wound Healing in Periodontal and Implant Surgery
}

\author{
Roberto Pippi ${ }^{\bowtie}$ \\ Department of Oral and Maxillofacial Sciences, Sapienza University of Rome, Italy \\ $\triangle$ Corresponding author: Roberto Pippi, Department of Oral and Maxillofacial Sciences, Sapienza University of Rome, Via Caserta 6, 00161 Rome, Italy \\ Telephone: +390649976651; fax: +390644230811 E-mail: roberto.pippi@uniroma1.it \\ (C) Ivyspring International Publisher. This is an open access article distributed under the terms of the Creative Commons Attribution (CC BY-NC) license \\ (https://creativecommons.org/licenses/by-nc/4.0/). See http://ivyspring.com/terms for full terms and conditions.
}

Received: 2017.02.19; Accepted: 2017.05.21; Published: 2017.07.18

\begin{abstract}
Clinical features of surgical soft tissue wound healing in dentistry have been rarely discussed in the international literature. The aim of the present paper is to highlight both the main clinical findings of surgical wound healing, especially in periodontal and implant dentistry, and the wound healing monitoring procedures which should be followed. Wound inspection after careful food and plaque debridement is the essential part of wound healing monitoring. Periodontal and peri-implant probing should be performed only after tissue healing has been completed and not on a weekly basis in peri-implant tissue monitoring. Telephone follow-up and patient self-assessment scales can also be used the days following surgery to monitor the most common surgical complications such as pain, swelling, bleeding, and bruising.

Wound healing monitoring is an important concern in all surgical procedures since it allows to identify signs or/and symptoms possibly related to surgical complications.
\end{abstract}

Key words: evaluation index; follow-up; post-operative period; self-assessment.

\section{Introduction}

Wound healing monitoring after surgery is an important concern in dentistry. It has been extensively studied in the past, both in animals and in humans, and several studies have recently been carried out to review all knowledge about clinical and histological features of uncomplicated oral wound healing. However, no indications have been comprehensively reported on how wound healing monitoring should be performed after specific surgical procedures. The aim of the present study is to therefore highlight how the healing process of the most common periodontal and dental implant procedures should be managed and which signs and symptoms more commonly occur after surgery.

\section{Wound Healing: The Context}

Basically there are two different kinds of wound healing: primary and secondary intention healing1, 2 . In primary intention healing there is no loss of tissue and all tissues are replaced in the same anatomic position and with the same structure they had before injury, although this definition is usually referred to as healing which occurs when the lining tissues are closely approximated surgically to perfectly cover all underlying injured tissues. This kind of healing is quicker, involves minimal scarring and a lower risk of infection than secondary healing. Secondary healing, on the other hand, occurs in areas which are not covered by normally epithelialized tissue due to intentional (extraction sockets, apically repositioned flaps) or accidental (wounds with full thickness loss of substance) exposure, or due to an insufficient amount of lining tissue to be used for coverage. Furthermore, the term tertiary intention is used to define delayed healing which occurs in both types of healing after an infected wound is left open for days until the infection disappears and is completely covered by surgical closure of the overlying tissue ${ }^{1,2}$. Lastly, a fourth type of wound healing can also be considered when the overlying tissue is partially lost (abrasion) or intentionally removed (epithelialized free gingival 
graft donor site), so a de-epithelialized connective tissue layer is exposed and heals by re-epithelialization from the normal contiguous epithelium².

Although oral surgical wounds heal in a very similar way, soft tissue healing is somewhat conditioned by that of the underlying bone tissue. First intention bone healing occurs in correctly repositioned and perfectly stabilized fractures, while secondary intention healing occurs when a bone defect has to be spontaneously filled, as in extraction sockets or in other post-surgical residual bone cavities or gaps ${ }^{3}$. A particular form of bone healing is that which occurs at the peri-implant surface level and can be defined as early or late stage healing. Early stage healing is that of a foreign body response and is influenced by implant stability and implant surface morphology and material. Both contact and distance osteogenesis allow to fill the gap between the host bone and the implant surface in this stage, resulting in immature woven bone. Late stage bone healing involves a remodeling process of both the host and immature bone which leads to the formation of mature lamellar bone which continues throughout life since it is significantly influenced by mechanical forms of stress ${ }^{4}$. Another kind of bone healing is bone graft healing which involves 3 different mechanisms: osteogenesis, osteoinduction and osteoconduction ${ }^{3}$. Osteogenesis represents new bone formation from graft osteocompetent cells. Osteoinduction is the stimulation of recipient bed mesenchymal cells to form bone by graft inductive proteins. Osteoconduction is when bone forms in and around the recipient graft bed. A new blood supply is essential in all kinds of bone healing and a complete coverage by normally healing overlying soft tissue is necessary for normal underlying bone healing.

Typical healing in dentistry refers to periodontal tissue healing which occurs differently in regenerative versus resective procedures and in the latter, in first intention versus secondary intention closure. Regenerative procedures aim to produce new periodontal tissue as in guided tissue regeneration $(\mathrm{GTR})^{5,6}$, while the aim of resective procedures is to remodel the existent periodontal tissues in order to eliminate the pockets and to facilitate oral hygiene maintenance. In first intention procedures, soft tissue flaps are repositioned to perfectly cover the underlying hard tissue, while, in secondary intention procedures, surgical flaps are placed in close proximity to the remodeled hard tissue to allow best new soft tissue attachment ${ }^{7}$.

\section{Healing Monitoring}

Post-surgical wound healing monitoring is mainly performed by wound inspection after careful food and plaque debridement.

Suture monitoring and removal after proper evaluation of soft tissue healing progression is also an integral part of wound healing monitoring. Since sutures have been shown to exert both an adverse influence on flap blood circulation and an inflammatory reaction in surrounding tissues, they should be removed according to each individual situation and not after a routine 7-10 day period ${ }^{8}$, although their early removal may lead to dehiscence of the wound margins ${ }^{9}$ and may negatively influence the surgical outcome of randomized clinical trials on the use of coronally advanced flap for root coverage as shown by a recent review ${ }^{10}$. Moreover, loose sutures do not play a role in wound healing; however, they can be pulled off during function causing tissue lacerations which can interfere with the healing process, so they should be removed early. Lastly, when a muco-periosteal flap is replaced in its pre-surgical position rather than an apical one, sutures should be removed later than 7-10 days since flap adherence to the root surface is impeded by early gingival epithelial cell apical migration ${ }^{11}$.

Probing of periodontal and peri-implant soft tissue is another important tool in post-surgical clinical monitoring but it should not be performed before tissue healing is complete, usually 2 weeks after sub-gingival scaling and root planing ${ }^{12,13}$ and 2 months after both gingivectomy ${ }^{14}$ and implant prosthesis application ${ }^{15}$. However, probing re-evaluation after scaling and root planing should be performed after 4 weeks, when soft tissues reach complete maturation and the patient has had sufficient time to acquire practice with oral hygiene techniques ${ }^{16}$.

A reduced mouth opening (trismus) caused by masticatory muscle contraction as a response to surgical trauma or to direct needle puncture during inferior alveolar nerve block ${ }^{17,} 18$ rarely occurs after periodontal and implant surgery in the lower jaw and slowly resolves in 1-2 weeks. Trismus may impede post-surgical examination and can make oral hygiene procedures, chewing and swallowing difficult, thus, making the post-operative course uncomfortable.

Scheduling post-operative visits is somewhat different, depending on the type and complexity of surgery, occurrence of intra-operative accidents, risk of post-surgical complications, surgeon experience, patient compliance, and possible application of periodontal dressing. If no surgical accidents occur and no dressing is applied, the first follow-up visit can be scheduled 1 week after surgery ${ }^{18-20}$, when the suture is usually removed, and at least another post-operative visit is recommended at the second or 
third week. Patients undergoing regenerative therapies with membranes should be seen more frequently during the first 2-3 weeks for professional tooth cleaning and to allow early discovery of any flap dehiscence with possible membrane or graft material exposures $^{21}$. In these patients suture removal is usually postponed from $10^{22}$ to $14^{23}$ days after surgery, until complete tissue healing occurs, although at 14 days some sutures can be $\operatorname{lost}^{24}$, at which point they should be seen for monitoring every 1-2 weeks ${ }^{23}$. Since regenerative procedures require that sutures be left in for a longer period, a careful choice of suture materials is of paramount importance. Actually, while an acute inflammatory reaction is common for all suture materials, being more evident at the third post-operative day mainly due to the trauma induced by the suture insertion, a more prolonged and intense inflammation is variably associated with different suture materials due to the migration of bacteria and other contaminants from the oral environment alongside the suture material ${ }^{24}$. For example, expanded polytetrafluoroethylene (e-PTFE) seems to induce a weaker inflammatory response and more rapid tissue repair. Moreover, monofilament sutures seem less able to conduct bacteria than braided sutures ${ }^{24}$. The choice of appropriate suture material and the correct timing for its removal are therefore crucial in reducing wound inflammation and improving tissue healing.

Table 1. Features which should be observed during wound healing after uncomplicated periodontal and dental implant surgery.

Swelling (at the surgical site, at distant sites)

Fever

Bleeding

Redness

Dehiscence, lacerations and ulcerations

Exudate (amount, color, consistency, odor)

Pain (spontaneous or on palpation)

Membrane (resorbable or not resorbable) or graft material exposure

Necrotic tissue

Flap instability

Suture loosening

Periodontal dressing instability

Tooth/implant mobility

Food debris or foreign bodies

Plaque (wound surfaces, involved teeth, all other teeth)

Epithelialization degree in secondary intention healing

Bad taste

Malodor

Fistulae

At each visit, all symptoms should be inquired and all clinical signs should be observed (Table 1$)^{25}$, taking into account that wound closure is delayed both in older adults and in women, thus these patients require more attentive post-surgical care ${ }^{26}$. Moreover, complications such as bleeding, infections, swelling or adverse tissue changes occur in about $50 \%$ of patients, however, they are severe in less than $1 \%$ of cases. They seem to occur more often in the anterior segments and are more pronounced in osseous surgery, possibly due to a greater extent of bone exposure ${ }^{27}$. Specifically, infections defined as increasing and progressive swellings with detectable suppuration are rarely observed after periodontal and implant surgery and only slightly more frequently in cases of dressing application ${ }^{28}$.

Soft tissue painless swelling usually occurs at the surgical site from the second day. This swelling is therefore directly proportional to the extension and duration of the procedure and it tends to progressively and spontaneously decrease from the 3 rd or 4 th day on ${ }^{29,} 30$. Slight swelling and redness are common at the insertion point of sutures, usually more pronounced in the vestibular mucosa than in the ridge area and sometimes associated with a small area of ulceration ${ }^{24}$. Swelling is somewhat unusual at distant locations such as the ipsilateral cheek and sub-mandibular region, due to edema and inflammation diffusion from the surgical site caused by surgical trauma ${ }^{19}$. Rarely, sub-mandibular lymph nodes may swell and be painful on palpation. A slight rise in temperature may also occur for a few hours after surgery due to transient bacteremia ${ }^{19}$. Light bleeding is common for the first few hours after surgery but it may occur after hours or continue for 2-3 days due to suture loosening, flap instability or dehiscence. Ecchymoses and hematomas may occur after 2-4 days and are caused by blood escape from the surgical site into the sub-mucosal and, rarely, into the sub-cutaneous soft tissues. Therefore, they are frequent in surgical procedures in which incisions are performed for flap release 29,30 , such as coronally positioned flaps for root coverage or regenerative procedures. Dehiscence may occur along the sutured incisions due to early suture loosening/breakage or marginal tissue laceration due to excessive wound tension, especially if associated to flaps which are too thin, sutures which are too close to the incision line, thick suture threads $(>4-0)$ or traumatic flap management ${ }^{8}, 31$. Exudate is often mistaken for bad healing, while it is a physiological event which carries out basic functions such as aiding migration of tissue-repairing cells, providing nutrients for cell metabolism, and enabling the diffusion of immune and growth factors 25,32 . Oral mucosal wounds do not usually allow detection of physiological exudation because of the presence of saliva. An increased amount of exudate is typical of the initial stage of healing, while late exudation may indicate a change in the healing process with a chronic inflammation or a 
superimposed infection. The normal exudate color (clear, amber, serous) is often difficult to distinguish from that of saliva. A cloudy exudate may indicate the presence of fibrin strands (fibrinous exudate) and is typical of inflammatory responses. On the other hand, a milky or creamy exudate (purulent exudate) may be caused by white blood cells and bacteria and therefore may be related to an infection. A pink or red exudate is clearly related to the presence of red blood cells (bleeding or blood-stained exudate) due to capillary damage ${ }^{25,} 32$ which is usually trauma-induced and is related to the instability of the wound edges or to the functional activity in the case of a secondary or fourth intention healing exposed surface. The exudate consistency varies with its nature, so infection exudates are very viscous due to a high protein or foreign material content (dressing residues or necrotic material) 25,32 . Consistency usually increases with the degree of infection and with the amount of foreign material. The exudate odor is also an important feature which should be noted since it may indicate a change in wound status. Anaerobic microbial contamination has a typical fetid odor. Malodor is also perceived at dressing removal due to food debris below. Pain is common but not always present after periodontal and dental implant surgeries, although it is still mild to moderate and short-term. It starts approximately a few hours after surgery, then it usually gradually decreases and ends after 24-48 hours $^{30}$. Males seem to experience pain significantly less than females ${ }^{27}$, although a recent study did not find any statistical difference in age, gender, systemic health and smoking between two groups of subjects, one with mild and the other with moderate-severe perceived pain $^{33}$. Pure muco-gingival procedures seem to be more painful than osseous surgery, which is more painful than soft tissue plastic surgery ${ }^{27}$. Technical differences among those procedures with different bone connective tissue exposure may account for different pain experiences after those procedures ${ }^{27}$, with extensive surgeries more likely to be associated to pain than less invasive surgeries ${ }^{33}$. Therefore, implant placement with guided bone regeneration causes much more intense and longstanding pain than other periodontal and implant surgeries $^{29}, 30,33$. Much of the experienced pain and discomfort is affected by the patient's pre-operative state of mind and expectations, although it is also related to the duration of surgery 27,30 , which could increase patient's anxiety and stress with consequent higher level of pain perception ${ }^{33}$. Post-surgical pain may also be related both to wide areas of bone exposure at the donor site and to the compression with resulting ulceration caused by an overextension of the surgical dressing, especially on the frena or the alveolar mucosa apically to the mucogingival junction ${ }^{19}$. A direct independent statistical association was also found between pain perception and amount of administered anesthetics, probably due to the related tissue distension ${ }^{33}$. Sometimes pain may be related to recurrent single or multiple herpetic lesions which occur on the keratinized mucosa of both the palate and the gingiva, near the surgical site, due to surgical trauma ${ }^{34}$. These lesions may be very painful during the first 3-7 days and tend to gradually reduce their tenderness as days go by until spontaneous complete resolution in about 7-14 days. Dentin hypersensitivity is commonly experienced after periodontal treatments, more frequently during the third post-operative week $^{35}$, especially after scaling and root planing, but also in cases of treatment-induced gingival recessions ${ }^{36}$ and following regenerative procedures for treatment of deep intrabony defects, with or without enamel matrix derivatives ${ }^{35}$. It may be induced by thermal (especially cold ones), mechanical (tooth brushing or touching with hard instruments) or chemical (sweets or citrus fruits) stimuli and it may be so severe that it may prevent an adequate patient plaque $\operatorname{control}^{19}$. Therefore, the dentist may provoke painful stimulation during monitoring visits, especially after dressing removal, during food and debris removal by means of the air-water spray or by metallic instruments.

Telephone follow-up can also be used to monitor the initial phase of post-surgical healing. It is fast, inexpensive and does not require high patient compliance, compared to the burden of both a questionnaire to be filled out at home and sent to the surgeon by mail and a clinical follow-up in the office. Moreover, telephone follow-up increases the patient's trust and confidence in the surgeon and improves the doctor-patient relationship since it gives the patient the impression that the surgeon is showing real interest in his/her post-operative conditions. Telephone monitoring allows to inquire post-surgical signs and symptoms such as pain, discomfort, swelling, bleeding, exudation, dressing mobility, bad taste, interference with daily activities, and temperature increase (also at the level of skin swellings) in order to assess whether the post-surgical course is normal or not and to decide whether the patient should return for clinical monitoring of wound healing. Some of these features, such as pain, swelling, bleeding and bruising, may be inquired with self-assessment numerical or verbal scales $27,29,30,33,37,38$.

A perfect knowledge of the clinical evolution of the healing process in each kind of surgery is essential in order to correctly interpret the wound's clinical appearance. 
In spontaneous healing after non-surgical (flapless) tooth extraction, the post-extraction socket is immediately filled by a blood clot which is completely replaced by a progressively increasing granulation tissue density within 2-7 days ${ }^{39,40}$. Epithelialization from the peripheral gingival margins starts within 24 hours and becomes complete after 1-5 weeks in relation to socket width and local traumatic factors, smoking, tooth location and concomitant extraction of adjacent teeth ${ }^{39,41}$. The top surface of the post-extraction socket remains concave for about 1 month due to incomplete new bone formation, and afterwards an overall reduction of residual edentulous crest volume occurs over time, more so in the horizontal plane than in the vertical plane ${ }^{42,43}$, more so at the buccal site than at the lingual/palatal one ${ }^{44}$, and especially during the first 3 months (two thirds) but also during the next 9 months (one third) ${ }^{41}$. After 1 year, in maxillary incisor and premolar sites, the residual alveolar bone is triangular-shaped due to a higher bone resorption in its coronal third and a progressive reduction of bone resorption going toward its apical portion ${ }^{45}$. In the posterior areas, on the contrary, alveolar bone loss especially occurs in the vertical plane ${ }^{41}$. Socket grafting procedures or mechanical barrier application seem to reduce ridge contraction after tooth extraction ${ }^{44}$. Post-extraction socket grafting with xenograft and allograft seems to result in less bucco-lingual/palatal socket reduction compared to allografts and no grafting after a 12-week healing period ${ }^{46}$

Immediately after scaling, root planing and curettage, the gingival margin appears hemorrhagic, brilliant red, and not adhering to the tooth. After 1 week an apical shift of its position occurs and it appears slightly redder than normal but much less so than the previous days. After 2 weeks it becomes normal in color, consistency, surface texture, and contour, and well-adapted to the tooth ${ }^{47}$. Tooth mobility often increases immediately after treatment and it slowly decreases during the first week after surgery, more often reaching better values than pre-operative ones after 2 weeks ${ }^{48}$. Considerable mobility with tooth displacement may occur due to both excessive bone and periodontal ligament removal during surgical ostectomy/osteoplasty and resorption caused by post-operative infection ${ }^{49}$. Tooth sensitivity to percussion may also be present and gradually disappears in a few days due to slight periodontal ligament inflammation ${ }^{19}$. Excess of periodontal dressing which interferes with the occlusion may also be responsible for tooth sensitivity during mastication ${ }^{19}$.

The gross appearance of a free gingival or a connective tissue graft closely stabilized on a recipient bed of gingival connective tissue and periosteum reflects its tissue changes. At the time of transplantation it is pale due to vessel emptiness. In 2 days it becomes grayish white due to the ischemia, and then it gradually changes to a normal pink thanks to its progressive neo-vascularization (4-11 days) $)^{50}$. Moreover, the graft initially appears swollen and soft due to plasma accumulation and then gradually becomes normal when the edema resolves thanks to new blood vessels ${ }^{51,52}$. The surface appearance of the free gingival graft is initially smooth and shiny, however, after 2-3 days it becomes grainy and similar to that of the connective tissue graft due to the progressive epithelial cell loss and granulation tissue formation ${ }^{52,53}$. Subsequently, the superficial layer of the graft becomes veil-like, thin and gray following new epithelialization from adjacent tissues, and, from the $4^{\text {th }}-5^{\text {th }}$ day to the $10^{\text {th }}-11^{\text {th }}$ day, it gradually acquires the typical features of a normal epithelium, with progressive maturation and keratinization starting from the 4th week ${ }^{50,54}$. A red area of tissue inflammation is clearly evident during the first week after surgery all around the graft and gradually disappears during the following 3-4 days ${ }^{51}$. A slight delay in wound healing is detectable in grafts placed on denuded bone compared to those placed on periosteum ${ }^{53}$. In all soft tissue graft procedures, a $25-45 \%$ tissue shrinkage typically occurs during the first month following surgery55,56, which is more evident in grafts retained on periosteum than in grafts placed on denuded bone ${ }^{53}$. No graft mobility is detectable on gentle palpation at 1 week for both grafts placed on the periosteum and those placed on denuded bone ${ }^{53}$.

In this kind of procedure, the donor site should also be monitored until complete restitutio ad integrum takes place, especially in free gingival grafts. Perceived pain is mostly pronounced the day after surgery and decreases gradually until it completely disappears within 2 weeks ${ }^{37}$. This reflects the 3 phases of fourth intention healing in that site. During the first phase, which was shown to be delayed by stress events ${ }^{57}$, the wound area is progressively (1-3 days) covered by an exudate or/and by a blood clot layer which acts as a protection mechanism from external stimuli. In the second phase (4-10 days), epithelial cells migrate from the adjacent tissues to completely cover the denuded area. Finally, during the maturation phase (11-42 days), the epithelial layer becomes normally keratinized ${ }^{37,58}$. It is worth noting that pain perception is directly related to the graft thickness and inversely related to the residual thickness of the palatal mucosa at the donor site, while graft width does not affect pain perception ${ }^{37}$. Sensitivity alterations may also occur at the donor site 
after removal of the tissue fragment to be grafted, and sensory recovery should therefore be monitored as well. It can be carried out by carefully prickling and rubbing the healing mucosa with the sharp end of a periodontal probe and asking the patient how different the sensation is, compared to the same actions carried out on the healthy palatal mucosa of the contra-lateral side. The return to normality usually occurs within 4-8 weeks ${ }^{58,59}$. In mucogingival procedures, as in all plastic surgeries, follow-up implies monitoring surgical outcome maintenance over time, i.e. gingival margin position coronal to the cement enamel junction (CEJ) in root coverage procedures, or gingival height and thickness in soft tissue graft procedures.

In case of gingivectomy ${ }^{14,19,56,60}$, the exposed area is immediately protected by a blood clot which is replaced by granulation tissue during the first days. The latter rapidly develops toward connective tissue, grows coronally and becomes epithelialized after 5-14 days, so a new free gingival margin and sulcus are reformed. Complete epithelialization is reached in about 1 month, while complete connective tissue repair takes 7-8 weeks. After this, no differences are visible between the treated area and the contiguous tissue. All these changes considerably vary from one individual to another, in relation to the surgical technique used (conventional scalpel, different lasers, electro-scalpel, abrasive tips), extent of the exposed area, and surgical site.

In all flap surgeries, during the first 1-2 weeks the flap is still more susceptible to dislodgement since its adherence to the underlying hard tissues is only guaranteed by the consolidating blood clot $23,61,62$. Therefore, provided that adequate flap stabilization is obtained and maintained by the correct suturing technique ${ }^{63}$, especially during the first days, spontaneous or function-related flap mobility disturbs clot arrangement and therefore induces bleeding from the incision lines and from the gingival margin, also delaying wound healing. For this reason no pressure should be exerted on it at the first follow-up visit. Tissue healing is therefore faster if no mechanical trauma is applied on the flap, especially during the first week after surgery 63 , also excluding any intrinsic tension by flap passive adaptation and, if inter-dental tissue preserving techniques are used, for better flap stabilization ${ }^{56}$. Plaque and food debris can be found on sutures and should be carefully removed with a cotton pellet to inspect all incision margins. From 7-14 days after surgery, the flap is still susceptible to mechanical trauma and after only $4-5$ weeks it is completely reattached to bone and teeth so no differences with the neighboring tissue are present ${ }^{56,61,64}$.

In regenerative procedures, especially in guided bone regeneration (GBR) procedures, the loss of labial, lingual or/and buccal sulcus depth is the natural consequence of the surgical technique in order to guarantee passive adaptation of surgical flaps for complete and lasting coverage of the augmented surgical area. No palpation should be applied to such areas to avoid dislocation of graft materials or membranes and careful inspection should be performed for early detection of any graft material or membrane exposure or loss of grafted material in the form of granules, chips or particles.

If a surgical dressing is applied, at dressing removal 1 week after surgery, in the case of gingivectomy ${ }^{19}$, or at the donor site, in free gingival grafting procedures ${ }^{65}$, a thin, friable and easily bleeding layer of new epithelium is found to cover the gingival cut surface, whereas in flap surgery, a thin yellowish-white layer of food debris that infiltrates below the pack covers the epithelial wound surfaces and should be carefully removed with a cotton pellet to verify their integrity ${ }^{19}$. At this moment, the incision lines already appear epithelialized, although bleeding may still occur on palpation ${ }^{19}$. The exposed root surfaces should then be examined in order to verify that all calculus has been removed.

A healing index was proposed by Landry, Turnbull and Howley ${ }^{66,67}$ to describe the extent of clinical healing after periodontal surgery and it was also recently modified to be used for extraction socket healing ${ }^{68}$. In the first case (Table 2), healing was estimated with a 5-level score index evaluated with the following 4 parameters: tissue color, response to palpation, granulation tissue, and incision margin ${ }^{66,67}$. In the modified index, the following evaluation parameters were proposed for post-extraction sites by applying a dichotomic score $(0 / 1)$ with a total score of 7: presence/absence of redness; presence/absence of granulation tissue; presence/absence of suppuration; presence/absence of swelling; degree of tissue epithelialization (partial/complete); presence/ absence of bleeding; presence/absence of pain on palpation ${ }^{6}$.

The wound evaluation scale (WES) can also be used. It addresses 6 clinical variables, each one with a $1 / 0$ (not present/present) score for a maximum total score of 6: step-off borders, contour irregularities (puckering), wound margin separation greater than 2 $\mathrm{mm}$, edge inversion (sinking, curling), inflammation (redness, discharge), and overall cosmetic appearance (well/not well) 69,70 . 
Table 2. Healing Index of Landry, Turnbull and Howley65,66

\begin{tabular}{|c|c|c|c|c|c|}
\hline Healing index & Tissue color & Bleeding on palpation & Granulation tissue & Incision margin & Suppuration \\
\hline $\begin{array}{l}1 \text { - Very Poor: } 2 \text { or more } \\
\text { signs are present }\end{array}$ & $\geq 50 \%$ of red gingiva & yes & yes & $\begin{array}{l}\text { not epithelialized, with loss of } \\
\text { epithelium beyond incision margin }\end{array}$ & yes \\
\hline 2 - Poor & $\geq 50 \%$ of red gingiva & yes & yes & $\begin{array}{l}\text { not epithelialized, with exposed } \\
\text { connective tissue }\end{array}$ & no \\
\hline 3 - Good & $25-50 \%$ of red gingiva & no & no & no exposed connective tissue & no \\
\hline 4 - Very Good & $<25 \%$ of red gingiva & no & no & no exposed connective tissue & no \\
\hline 5 - Excellent & all pink tissues & no & no & no exposed connective tissue & no \\
\hline
\end{tabular}

In dental implant surgery without bone augmentation procedures soft tissue healing differs from standard 2-stage procedures in which soft tissues completely cover the surgical bed to 1-stage procedures in which soft tissues are closely adapted around the implant neck which is left outside the surgical wound with a healing abutment or a provisional prosthesis ${ }^{71}$. In this last condition, soft tissue healing is similar to that of the second stage of standard implant surgery performed for healing abutment connection in which wound margins are closely approximated to the abutment ${ }^{56}$. In every case, a blood clot immediately fills the space between the implant cover screw or implant abutment/neck and the adjacent soft tissues, so that bleeding occurs on flap palpation through wound incisions or at the abutment-tissue margin interface during the first 2-3 days $^{56}$. In completely covered implants, first intention soft tissue healing occurs in about 2 weeks, while in all other cases the connective tissue aspect of the flap at the abutment-flap interface is visible for 2-3 days, at which point complete epithelialization of the abutment facing soft tissue occurs and, after the first 2 weeks peri-implant epithelium starts to migrate apically. A 3-4 $\mathrm{mm}$ high mature soft tissue barrier adjacent to titanium implants with about $60 \%$ of a new epithelium attachment ${ }^{72}$ is completely formed within 8 weeks ${ }^{56,73,74}$ and remains stable for at least 12-15 months, possibly reaching a greater final width in procedures different from conventional 2-stage procedures with implant insertion in healed sites ${ }^{56}$. Therefore, peri-implant probing should not be performed earlier than 2 months after soft tissue adaptation to abutment or provisional prosthesis, to avoid dimensional and structural changes of the mucosal seal ${ }^{15}$. Furthermore, although a $0.20 \mathrm{~N}$ probing does not seem to compromise implant health, 5 days were shown to be necessary for complete reestablishment of peri-implant epithelial attachment after probing, therefore frequent probing should be avoided ${ }^{75}$. Occlusal prosthesis monitoring should also be performed at every follow-up visit in post-extraction implants with immediate insertion and loading to detect any developing functional overloading or disclosing interferences which can obstruct early tissue healing and osteo-integration ${ }^{76}$.

\section{Conclusion}

Wound healing monitoring should always be performed for an early identification of signs and/or symptoms possibly related to surgical complications. Different clinical findings are associated to different kinds of wound healing in different surgical procedures and surgeons should be aware of such findings to guarantee prompt intervention and thus avoid worsening.

\section{Competing Interests}

The authors have declared that no competing interest exists.

\section{References}

1. Messadi DV, Bertolami CN. General principles of healing pertinent to the periodontal problem. Dent Clin North Am 1991;35(3):443-457.

2. Hupp JR. Wound repair. In: Peterson LJ, Ellis E, Hupp JR, Tucker MR. Contemporary oral and maxillofacial surgery. 4th ed. Mosby, Inc. 2003.

3. Sándor GKB, Carmichael RP, Ylikontiola LP, et al. Healing of large dentofacial defects. Endod Topics 2012;25:63-94.

4. Davies JE. Understanding peri-implant endosseous healing. J Dent Educ 2003;67(8):932-949.

5. Gottlow J, Nyman S, Karring T, et al. New attachment formation as the result of controlled tissue regeneration. J Clin Periodontol 1984;11(8):494-503.

6. Gottlow J, Nyman S, Lindhe J, et al. New attachment formation in the human periodontium by guided tissue regeneration. Case reports. J Clin Periodontol 1986;13(6):604-616.

7. Carranza FA, Takei HH. The flap technique for pocket therapy. In Newman MG, Takei HH and Carranza FA. Carranza's Clinical Periodontology. 9th ed. W.B. Saunders Co. 2002

8. Burkhardt R, Lang NP. Role of flap tension in primary wound closure of mucoperiosteal flaps: a prospective cohort study. Clin Oral Implants Res 2010;21:10-14.

9. Atterbury RA, Vazirani SJ. Removal of sutures following oral surgery. Oral Surg Oral Med Oral Pathol 1961;14(6):658-661.

10. Tatakis DN, Chambrone L. The effect of suturing protocols on coronally advanced flap root-coverage outcomes: a meta-analysis. J Periodontol 2016;87:148-155.

11. Wennströmm J, Heijl L, Lindhe J. Periodontal surgery: access therapy. In Lindhe J. Clinical periodontology and implant dentistry. 3rd ed. Munksgaard, Copenhagen 1997.

12. Stahl SS, Weiner JM, Benjamin S, et al. Soft tissue healing following curettage and root planing. J Periodontol 1971;42(11):678-684.

13. Waerhaug J. Healing of the dento-epithelial junction following subgingival plaque control. 1. As observed in human biopsy material. J Periodontol 1978:49(1):1-8.

14. Novaes AB, Kon S, Ruben MP, et al. Visualization of the microvascularization of the healing periodontal wound. III Gengivectomy. J Periodontol 1969;40(6):359-371.

15. Schwarz F, Mihatovic I, Ferrari D, et al. Influence of frequent clinical probing during the healing phase on healthy peri-implant soft tissue formed at different titanium implant surfaces: a histomorphometrical study in dogs. J Clin Periodontol 2010;37:551-562.

16. Perry DA, Schmid MO. Phase I periodontal therapy. In Newman MG, Takei HH, Carranza FA. Carranza's Clinical Periodontology. 9th ed. W.B. Saunders Co. 2002. 
17. Dhanrajani PJ, Jonaidel O. Trismus: aetiology, differential diagnosis and treatment. Dent Update 2002;29(2):88-92, 94.

18. Peterson LJ. Post-operative patient management. In: Peterson LJ, Ellis E, Hupp JR, Tucker MR. Contemporary oral and maxillofacial surgery. 4th ed. Mosby, Inc. 2003.

19. Klokkevold PR, Carranza FA, Takei HH. General principles of periodontal surgery. In Newman MG, Takei HH, Carranza FA. Carranza's Clinical Periodontology. 9th ed. W.B. Saunders Co. 2002.

20. McGlumphy EA, Larsen PE. Contemporary implant dentistry. In: Peterson LJ, Ellis E, Hupp JR, Tucker MR. Contemporary oral and maxillofacial surgery. 4th ed. Mosby, Inc. 2003.

21. Karring T, Lindhe J, Cortellini P. Regenerative periodontal therapy. In Lindhe J. Clinical periodontology and implant dentistry. 3rd ed. Munksgaard, Copenhagen 1997.

22. Aguirre-Zorzano LA, Estefanía-Cundín E, Gil-Lozano J, et al. Periodontal regeneration of intrabony defects using resorbable membranes: determinants of the healing response. an observational clinical study. Int J Periodontics Restorative Dent 1999;19:363-371.

23. Sculean A, Stavropoulos A, Windisch $\mathrm{P}$, et al. Healing of human intrabony defects following regenerative periodontal therapy with a bovine-derived xenograft and guided tissue regeneration. Clin Oral Implants Res 2004;8:70-74.

24. Selvig KA, Biagiotti GR, Leknes KN, et al. Oral tissue reactions to suture materials. Int J Periodontics Restorative Dent 1998;18(5):475-487.

25. [Internet] Northern Sydney Central Coast Area Health Service (NSCCAHS). Wound assessment guidelines; Nov 18, 2008. http://bishopkeough.org/ download-now/nsccahs-wound-assessment-guidelines-download.pdf

26. Engeland CG, Bosch JA, Cacioppo JT, et al. Mucosal wound healing. The role of sex and age. Arch Surg 2006;141:1193-1197.

27. Curtis JW Jr, McLain JB, Hutchinson RA. The incidence and severity of complications and pain following periodontal surgery. J Periodontol 1985;56:597-601.

28. Powell CA, Mealey BL, Deas DE, et al. Post-surgical infections: prevalence associated with various periodontal surgical procedures. J Periodontol 2005;76(3):329333.

29. Tan WC, Krishnaswamy G, Ong MMA, et al. Patient-reported outcome measures after routine periodontal and implant surgical procedures. J Clin Periodontol 2014;41:618-624.

30. Yao J, Lee KK, McGrath C, et al. Comparison of patient-centered outcomes after routine implant placement, teeth extraction, and periodontal surgical procedures. Clin Oral Implants Res 2016 Mar 11;0:1-8. doi: 10.1111/clr.12794. [Epub ahead of print]

31. Burkhardt R, Preiss A, Joss A, Lang NP. Influence of suture tension to the tearing characteristics of the soft tissues: an in vitro experiment. Clin Oral Implants Res 2008;19:314-319.

32. [Internet] World Union of Wound Healing Societies (WUWHS). Wound exudate and the role of dressings. A consensus document. Medical Education Partnership Ltd, London 2007. http://www.woundsinternational.com/ media/issues/82/files/content 42.pdf. Accessed on 2016, September 04.

33. Mei C-C, Lee F-Y, Yeh H-C. Assessment of pain perception following periodontal and implant surgeries. J Clin Periodontol 2016; 43: 1151-1159.

34. Brasher WJ, Rees TD, Boyce WA. Complications of free grafts of masticatory mucosa. J Periodontol 1975;46(3):133-138.

35. Tonetti MS, Fourmousis I, Suvan J, et al. Healing, post-operative morbidity and patient perception of outcomes following regenerative therapy of deep intrabony defects. J Clin Periodontol 2004;31:1092-1098.

36. Chabanski MB, Gillam DG, Bulman JS, et al. Prevalence of cervical dentine sensitivity in a population of patients referred to a specialist periodontology Department. J Clin Periodontol 1996;23(11):989-992.

37. Burkhardt R, Hämmerle CHF, Lang NP. Self-reported pain perception of patients after mucosal graft harvesting in the palatal area. J Clin Periodontol 2015;42:281-287.

38. Wewers ME, Lowe NK. A critical review of Visual Analogue Scales in the measurements of clinical phenomena. Res Nurs Health 1990;13:227-236.

39. Amler M II. Time sequence of tissue regeneration in human extraction wounds. Oral Surg Oral Med Oral Pathol 1963;27(3):309-318.

40. Lang NP, Becker W, Thorkild K. Alveolar bone formation. In Lindhe J. Clinical periodontology and implant dentistry. 3rd ed. Munksgaard, Copenhagen 1997.

41. Farina R, Trombelli L. Wound healing of extraction sockets. Endod Topics 2012;25:16-43.

42. Van der Weijden F, Dell'Acqua F, Slot DE. Alveolar bone dimensional changes of post-extraction sockets in humans: a systematic review. J Clin Periodontol 2009;36:1048-1058

43. Tan WC, Wong TLT, Wong MCM, et al. A systematic review of post-extractional alveolar hard and soft tissue dimensional changes in humans. Clin Oral Implants Res 2012;23(Suppl.5):1-21.

44. Araújo MG, Silva CO, Misawa M, et al. Alveolar socket healing: what can we learn? Periodontol 2000 2015;68:122-134.

45. Misawa M, Lindhe J, Araújo MG. The alveolar process following single tooth extraction: a study of maxillary incisor and premolar sites in man. Clin Oral Implants Res 2016;27(7):884-889.

46. Jambhekar S, Kernen F, Bidra AS. Clinical and histologic outcomes of socket grafting after flapless tooth extraction: A systematic review of randomized controlled clinical trials. J Prosthet Dent 2015;113:371-382.
47. Carranza FA, Takei HH. Gingival curettage. In Newman MG, Takei HH and Carranza FA. Carranza's Clinical Periodontology; 9th ed. W.B Saunders Co. 2002.

48. Lang NP, Tonetti MS. Periodontal diagnosis in treated periodontitis. J Clin Periodontol 1996;23:240-250.

49. Ruben MP, Kon S, Goldman HM, et al. Complications of the healing process after periodontal surgery. J Periodontol 1972;43(6):339-346.

50. Oliver RC, Löe H, Karring T. Microscopic evaluation of the healing and revascularization of free gingival grafts. J Periodontal Res 1968;3:84-95.

51. Janson WA, Ruben MP, Kramer GM, et al. Development of the blood supply to split-thickness free ginival autografts. J Periodontol 1969;40(12):707-716.

52. Takei HH, Azzi RA. Periodontal plastic and esthetic surgery. In Newman MG, Takei HH, Carranza FA. Carranza's Clinical Periodontology. 9th ed. W.B. Saunders Co. 2002.

53. James WC, McFall WT Jr. Placement of free gingival grafts on denuded alveolar bone - Part I: Clinical Evaluations. J Periodontol 1978;49(6):283-290.

54. Hawley CE, Staffileno H. Clinical evaluation of free gingival graft in periodontal surgery. J Periodontol 1970;41(2):105-112.

55. Wennströmm J, Pini Prato GP. Mucogingival Therapy. In Lindhe J. Clinical periodontology and implant dentistry. 3rd ed. Munksgaard, Copenhagen 1997.

56. Sculean A, Gruber R, Bosshardt DD. Soft tissue wound healing around teeth and dental implants. J Clin Periodontol 2014;41(Suppl. 15):S6-S22.

57. Marucha PT, Kiecolt-Glaser JK, Favagehi M. Mucosal wound healing is impaired by examination stress. Psychosom Med 1998;60:362-365.

58. Del Pizzo M, Modica F, Bethaz N, et al. The connective tissue graft: comparative clinical evaluation of wound healing at the palatal donor site. A preliminary study. J Clin Periodontol 2002;29:848-854.

59. Keceli HG, Aylikci BU, Koseoglu S, et al. Evaluation of palatal donor site haemostasis and wound healing after free gingival graft surgery. J Clin Periodontol 2015;42: 582-589.

60. Carranza FA. The gingivectomy technique. In Newman MG, Takei HH, Carranza FA. Carranza's Clinical Periodontology. 9th ed. W.B. Saunders Co. 2002.

61. Kon S, Novaes AB, Ruben MP, et al. Visualization of the microvascularization of the healing periodontal wound. IV. Mucogingival surgery: full thickness flap. J Periodontol 1969;40:441-456.

62. Sims TN, Ammons W. Resective osseous surgery. In. Newman MG, Takei $\mathrm{HH}_{\text {, }}$ Carranza FA. Carranza's Clinical Periodontology. 9th ed. W.B. Saunders Co. 2002.

63. Burkhardt R, Lang NP. Influence of suturing on wound healing. Periodontol 2000 2015;68:270-281.

64. Takei HH, Carranza FA. The periodontal flap. In Newman MG, Takei HH, Carranza FA. Carranza's Clinical Periodontology. 9th ed. W.B. Saunders Co. 2002

65. Farnoush A. Techniques for the protection and coverage of the donor sites in free soft tissue grafts. J Periodontol 1978;49(8):403-405.

66. Landry RG, Turnbull RS, Howley T. Effectiveness of benzydamyne $\mathrm{HCl}$ in the treatment of periodontal post-surgical patients. Res Clin Forums 1988;10:105-118

67. Masse JF, Landry RG, Rochette C, et al. Effectiveness of soft laser treatment in periodontal surgery. Int Dent J 1993:43:121-127.

68. Pippi R, Santoro M, Cafolla A. The effectiveness of a new method using an extra-alveolar hemostatic agent after dental extractions in older patients on oral anticoagulation treatment: an intra-patient study. Oral Surg Oral Med Oral Pathol Oral Radiol 2015;120:15-21.

69. Hollander JE, Singer AJ, Valentine S, et al. Wound registry: development and validation. Ann Emerg Med 1995;25:675-685.

70. Quinn JV, Wells GA. An assessment of clinical wound evaluation scales. Acad Emerg Med 1998;5:583-586.

71. Larjava H. Clinical aspects of wound healing in the oral cavity. Endod Topics $2012 ; 25: 1-3$

72. Villar CC, Huynh-Ba G, Mills MP, et al. Wound healing around dental implants. Endod Topics 2012;25:44-62.

73. Berglundh T, Abrahamsson I, Welander $\mathrm{M}$, et al. Morphogenesis of the peri-implant mucosa: an experimental study in dogs. Clin Oral Implants Res 2007;18:1-8.

74. Salvi GE, Bosshardt DD, Lang NP, et al. Temporal sequence of hard and soft tissue healing around titanium dental implants. Periodontol 2000 2015;68:135-152

75. Etter $\mathrm{TH}$, Hkanson I, Lang NP, et al. Healing after standardized clinical probing of the peri-implant soft tissue seal. A histomorphometric study in dogs. Clin Oral Implants Res 2002;13:571-580.

76. Warreth A, Doody K, Al-Mohsen M, et al. Fundamentals of occlusion and restorative dentistry. Part II: occlusal contacts, interferences and occlusal considerations in implant patients. J Ir Dent Ass 2015;61(5):252-259. 